\title{
Generation of electrical energy using lead zirconate titanate (PZT-5A) piezoelectric material: Analytical, numerical and experimental verifications ${ }^{\dagger}$
}

\author{
Zubair Butt ${ }^{1,{ }^{*}}$, Riffat Asim Pasha ${ }^{2}$, Faisal Qayyum ${ }^{2}$, Zeeshan Anjum ${ }^{2}$, Nasir Ahmad $^{1}$ and Hassan Elahi ${ }^{3}$ \\ ${ }^{1}$ Department of Mechanical, Mechatronics and Manufacturing Engineering,UET Lahore, Faisalabad Campus, Pakistan \\ ${ }^{2}$ Department of Mechanical Engineering, University of Engineering and Technology, Taxila, Pakistan \\ ${ }^{3}$ Northwestern Polytechnical University Xian, China
}

(Manuscript Received April 6, 2015; Revised April 4, 2016; Accepted April 6, 2016)

\begin{abstract}
Energy harvesting is the process of attaining energy from the external sources and transforming it into usable electrical energy. An analytical model of piezoelectric energy harvester has been developed to determine the output voltage across an electrical circuit when it is forced to undergo a base excitation. This model gives an easy approach to design and investigate the behavior of piezoelectric material. Numerical simulations have been carried out to determine the effect of frequency and loading on a Lead zirconate titanate (PZT-5A) piezoelectric material. It has been observed that the output voltage from the harvester increases when loading increases whereas its resonance frequency decreases. The analytical results were found to be in good agreement with the experimental and numerical simulation results.
\end{abstract}

Keywords: Energy harvesting; PZT-5A; Analytical modeling; Numerical simulation

\section{Introduction}

In present era the demand of low power electronic instruments has been increasing and their energy consumption is decreasing. With this increasing demand of low power electronics systems, the researchers focus on piezoelectric energy harvesting, which is a process of converting mechanical energy into electrical energy. Piezoelectric materials are attractive source for energy harvesting because they can be used directly to recharge the batteries and to provide power to other electronic accessories like communication devices, wireless sensors and they can easily be fabricated in different scales [13]. The ability of a material to produce electrical charges when mechanical stress is applied is known as direct effect of piezoelectric. The energy harvesting by using piezoelectric material uses direct piezoelectric effect [4]. Jacques Curie and Pierre Curie discovered the phenomenon of piezoelectricity in 1880 [5]. Continuous energy harvesting using piezoelectric element can be used to increase the efficiency of micro scale solar generator using wind power as the energy source [6]. Piezoelectric generator fabricated by using multiple circular piezoelectric harvester arrays can harvest energy over a wide range of frequency [7]. It was observed that the energy from the

\footnotetext{
*Corresponding author. Tel.: +92 3338673859

E-mail address: zubairbutt64@yahoo.com

${ }^{\dagger}$ Recommended by Editor Chongdu Cho

(C) KSME \& Springer 2016
}

harvester increases while its resonance frequency decreases when the pre-stress increases [8]. The electrical behavior of piezoelectric energy harvesters can be modeled analytically [9]. An ordinary differential equation of a system is difficult to model as a block diagram. The Laplace transformation is used to represent input, output and a system as separate entities [10]. Tabesh and Frèchette demonstrated a simple analytical design procedure for piezoelectric energy harvesters that determines the beam geometry and load impedance [11]. In 2002 Tanner et al. developed a stack type piezoelectric energy harvesting device [12]. A single degree of freedom analytical model was developed by Erturk and Inman in 2009 [13]. In 2009 a study reported on harvesting energy from band random vibration of piezoelectric system [14]. Fakhzan and Muthalif in 2013 presented an analytical evaluation of voltage generation of piezoelectric cantilever beam when subjected to base excitation [15]. In 2005 a study reported a design consideration related to the mechanical behavior of piezoelectric energy harvester [16]. Erthurk and Inman developed an analytical model to solve the response of cantilevered piezoelectric harvester based on Euler-Bernoulli's beam assumption [17]. Finite element simulations are a power full tool for the design and analysis [18-21] and these are used for solving complex geometries and nonuniform electric field [22]. Finite element analysis (FEA) models employ transducer experimental free amplification to establish the accuracy in the use of piezoelectric materials. 


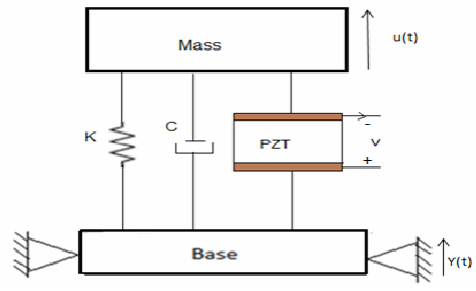

Fig. 1. Schematic diagram of piezoelectric energy harvester.

The FEA verification models simulate free extension of the transducer with a fixed boundary condition at one end to avoid rigid body motion [23]. In 1970 Allik and Hughes formulated the first linear piezoelectric finite element method [24].

In this research, a single degree of freedom electromechanical model was developed to determine the output voltages of rectangular shaped Lead zirconate titanate (PZT-5A) piezoelectric material at various frequency and loading conditions. The design model was validated with the experimental and simulation results. The ultimate goal of this paper is to provide traditional alternative and reduces the energy requirements of small electronic instruments such as Wireless sensor network (WSNS), health monitoring sensor and MEMS.

\section{Analytical modeling of piezoelectric system}

Consider a schematic figure of single degree of freedom energy harvesting system as shown in Fig. 1.

The structure comprises of a rigid mass ' $\mathrm{M}$ ' bonded on a spring ' $\mathrm{K}$ ', on a damper ' $\mathrm{C}$ ' and on a piezoelectric disc corresponding to the attached piezoelectric specimen. The copper electrodes acting as cathode and anode were placed on two major surfaces of the material. The electrodes were directly attached to an electrical circuit having resistance R. The displacement of the mass is $u(t)$ and $v(t)$ is the voltage through the piezoelectric layers. The voltages are generated due to the base excitation of the piezoelectric material. The $y(t)$ is the mass displacement due to base excitation and it is purely sinusoidal. So by using Newton's law of motion the electromechanical behavior of linear second order differential equations is given by:

$$
\begin{aligned}
& M \ddot{u}(t)+C \dot{u}(t)+K u(t)-\theta v(t)=-M \ddot{y}(t) \\
& C_{p} \dot{v}(t)+\frac{v(t)}{R}+\theta \dot{u}(t)=0 .
\end{aligned}
$$

Eq. (1) is a simple Newton's equation of motion when the system is electrically short (i.e. $v=0$ ), where ' $t$ ' is time, ' $u(t)$ ' is the mass displacement, ' $\mathrm{K}$ ' is the mechanical stiffness of system, ' $\mathrm{C}$ ' is the mechanical damping of the system and ' $y(t)$ ' is the displacement of the harvester due to base excitation. The electromechanical coupling coefficient ' $\theta$ ' is proportional to voltage ' $\mathrm{v}(\mathrm{t})$ ' across the harvester. Eq. (2) is obtained from an electrical circuit where ' $\mathrm{C}_{\mathrm{p}}$ ' is the capacitance of

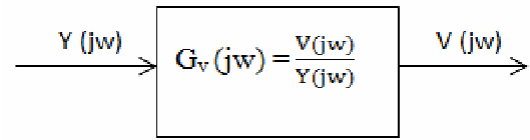

Fig. 2. Block diagram of voltage transfer function.

specimen. Taking the Laplace transform of Eqs. (1) and (2)

$$
\begin{aligned}
& M s^{2} u(s)+C s u(s)+K u(s)-\theta v(s)=-M s^{2} y(s) \\
& C_{p} s v(s)+\frac{v(s)}{R}+\theta s u(s)=0
\end{aligned}
$$

where' $s$ ' is the Laplace operator and ' $v(\mathrm{~s})$ ' and ' $\mathrm{u}(\mathrm{s})$ ' are the representation of voltage and displacement in Laplace domain. Now transforming both equations into frequency domain by substituting 's = jw' we get:

$$
\begin{aligned}
& \left(-M w^{2}+C j w+K\right) u(j w)-\theta v(j w)=M w^{2} y(j w) \\
& C_{p} j w v(j w)+\frac{v(j w)}{R}+\theta j w u(j w)=0
\end{aligned}
$$

where $v(j w), u(j w)$ and $y(j w)$ are the voltage and displacement in frequency domain and $\mathrm{w}$ is the angular frequency of the harvester. Now represent the Eq. (6) as function of displacement.

$$
v(j w)=-\frac{\mathrm{R} \theta \mathrm{jw} \mathrm{u}(\mathrm{jw})}{\mathrm{RCpjw}+1} .
$$

To obtain the output voltage as a function of displacement considered a voltage transfer function [10] of the form $G v(j w)=v(j w) / y(j w)$. The simplified block diagram of the energy harvester model is shown in Fig. 2.

Eq. (8) shows the linkage of displacement and voltage in frequency domain.

$$
G_{v}(j w)=\frac{v(j w)}{y(j w)}=-\frac{\mathrm{R} \theta \mathrm{jMw} w^{3}}{\left(\left(-\mathrm{Mw}^{2}+\mathrm{Cjw}+\mathrm{K}\right)(\mathrm{RCpjw}+1)+\mathrm{R} \theta^{2} \mathrm{jw}\right)} .
$$

As the voltages are generated due to the base excitation and the external excitation is sinusoidal with the frequency close to the resonance frequency of the harvester. At the resonance, the system has low viscous losses [9] and the simplified form of Eq. (8) is given below in Eq. (9)

$$
\frac{\mathrm{v}(\mathrm{jw})}{\mathrm{y}(\mathrm{jw})}=-\frac{R \theta M w^{2}}{\left(C+j w C R C_{p}+\theta^{2} R\right)} .
$$

As the piezoelectric system is in parallel mode, the material properties (model coefficients) of the system are given by Ref. [11]. 
Table 1. Material properties provided by the supplier.

\begin{tabular}{c|c}
\hline Description & Value \\
\hline Density $(\rho)$ & $7750 \mathrm{Kg} / \mathrm{m}^{3}$ \\
\hline Young modulus $(\mathrm{E})$ & $6.5 \times 10^{10} \mathrm{~N} / \mathrm{m}^{2}$ \\
\hline Mechanical quality factor $\left(\mathrm{Q}_{\mathrm{m}}\right)$ & 80 \\
\hline Piezoelectric voltage coefficient $\left(\mathrm{g}_{33}\right)$ & $24 \times 10^{-3} \mathrm{~V} \cdot \mathrm{m} / \mathrm{N}$ \\
\hline Piezoelectric strain coefficient $\left(\mathrm{d}_{33}, \mathrm{~d}_{31}\right)$ & $374 \times 10^{-12}-171 \times 10^{-12} \mathrm{~m} / \mathrm{volt}$ \\
\hline Dielectric constant $\left(\mathcal{E}_{33}{ }^{\mathrm{T}}\right)$ & $1.504 \times 10^{-8} \mathrm{~F} / \mathrm{m}$ \\
\hline Elastic compliance constant $\left(\mathrm{S}_{11}{ }^{\mathrm{E}}\right)$ & $16.4 \times 10^{-12} \mathrm{~m}^{2} / \mathrm{N}$ \\
\hline Initial depolarization field $\left(\mathrm{E}_{\mathrm{c}}\right)$ & $5 \times 10^{5} \mathrm{~V} / \mathrm{m}$ \\
\hline Polarization field $\left(\mathrm{E}_{\mathrm{p}}\right)$ & $2 \times 10^{6} \mathrm{~V} / \mathrm{m}$ \\
\hline Curie temperature & $350^{\circ} \mathrm{C}$ \\
\hline Thermal expansion coefficient & $\sim 4 \times 10^{-6 \circ} \mathrm{C}^{-1}$ \\
\hline
\end{tabular}

$$
C=\frac{4 \varepsilon_{33} \mathrm{LW}}{\mathrm{T}}, \quad K=\frac{W T^{3}}{4 L^{3} S_{11}}, \quad \theta=\frac{3 \mathrm{LWd}_{31}}{4 \mathrm{~T} \varepsilon_{33}}
$$

where $\mathrm{L}, \mathrm{W}$ and $\mathrm{T}$ are the length, width, and thickness of the specimen.

\section{Experimentation}

To check the accuracy of the analytical model an experimental setup has been developed. A rectangular shaped Lead zirconate titanate (PZT-5A) specimen has been selected for analysis due to its excellent dielectric, ferroelectric and piezoelectric properties. PZT-5A is an industry type 5A (Navy type II) piezoceramic. The specimen properties as provided by supplier are given in Table 1 .

The experimentally predicted data confirmed the validity of analytical model. The power output depends majorly upon the mechanical and piezoelectric material properties [25]. The experimental setup was designed in such a way that load cell was fixed on a base of mild steel iron sheet, clamped $12 \mathrm{~V} \mathrm{DC}$ motor with a cam shaft on it in such a way that it had screw mechanism to adjust its position and provide variable loading conditions. To operate the DC motor we designed a power supply to operate it at various volts and amperes as the principle of the motor is that on increasing its current, its speed increases or increase the load via screw mechanism. The DC motor could apply a maximum of $25 \mathrm{~N}$ force under wide range of frequency from 1-10000 Hz. The copper electrodes acted as cathode and anode was placed on the two major surfaces of the specimen. Fixed the specimen on a load cell in such a way that it's top and bottom both side faces copper electrodes. A full wave bridge rectifier consisting of 4 diodes (1N4001) connected in series with the electrodes to convert Ac voltage into Dc voltage. The load was applied on top surface of the piezoelectric material and monitored by using load cell (Model HYTEK). The function generator (HM-8150) was used to provide a series of sinusoidal signals at various frequency and voltage amplitudes. The capacitance was determined by using capacitance meter (DM-6013L). The resis-
Table 2. Materials properties used in simulation [26].

\begin{tabular}{c|c}
\hline Mechanical properties & PZT-5A \\
\hline Elastic coefficient $(\mathrm{GPa})$ & 121 \\
$\mathrm{C}_{11}$ & 75.40 \\
$\mathrm{C}_{12}$ & 75.20 \\
$\mathrm{C}_{13}$ & 111 \\
$\mathrm{C}_{33}$ & 21.1 \\
$\mathrm{C}_{44}$ & \\
\hline Piezoelectric coupling matrix $\left(10^{-12} \mathrm{~m} /\right.$ volt $)$ & 584 \\
$\mathrm{~d}_{15}$ & -171 \\
$\mathrm{~d}_{31}$ & 374 \\
$\mathrm{~d}_{33}$ & \\
$\mathrm{e}_{31}$ & -5.4 \\
$\mathrm{e}_{33}$ & 15.8 \\
$\mathrm{e}_{15}$ & 12.3 \\
\hline Piezoelectric coefficient $\left(\mathrm{C} / \mathrm{m}^{2}\right)$ & \\
$\varepsilon_{11}$ & 8.107 \\
$\varepsilon_{33}$ & 7.346 \\
\hline Dielectric constant $\left(10^{-9} \mathrm{~F} / \mathrm{m}\right)$ & \\
\hline
\end{tabular}

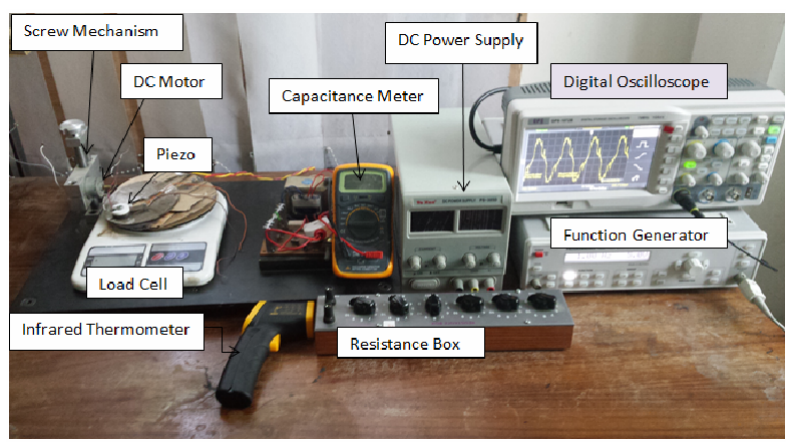

Fig. 3. Experimental setup.

tance was adjusted by using resistance box and displacement due to base excitation was determined by using dial indicator (MITUTOYO-2046S). The response was analyzed on a digital oscilloscope (GPS-1072B) at variable loading and frequency conditions. The experimental setup is shown in Fig. 3.

\section{Numerical simulation}

The analytical and experimental results were also verified with numerical simulation method. A 3D finite element model of a Lead zirconate titanate (PZT-5A) piezoelectric material was developed in ABAQUS ${ }^{\mathrm{TM}} /$ Standard software to study the effect of various loading and frequency conditions. The specimen was modeled as a 3D brick of length $20 \mathrm{~mm}$, width $10 \mathrm{~mm}$ and thickness $5 \mathrm{~mm}$. The relevant material properties used in ABAQUS are given in Tables 1 and 2.

Newton integration scheme has been used in ABAQUS. The ABAQUS developed 8 nodal first order linear hexahedral C3D8E coupled field elements. The final meshed model of PZT-5A contains 8000 hexahedral elements and 9471 nodes. A dynamic analysis has been carried out where a uniformly distributed load is applied on the top surface of the piezoelectric material along their polarization directions. The bottom 


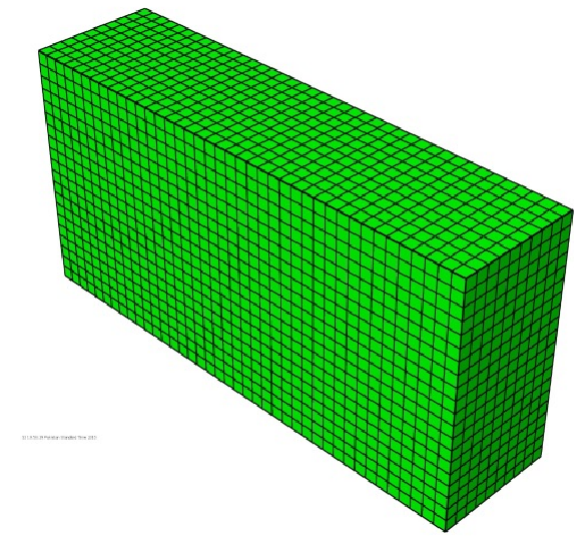

Fig. 4. Meshed model in ABAQUS.

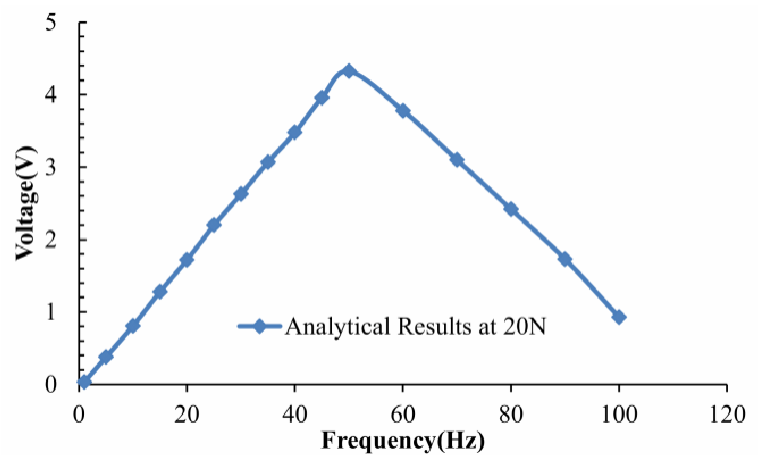

Fig. 5. Analytical model data at $20 \mathrm{~N}$ and variable frequency range.

surface of the specimen was grounded. A vertical load is applied on a specimen and the corresponding electrical potential (V) was obtained under variable frequency due to base excitation. Fig. 4 shows the meshed model of PZT-5A with an approximate global size of 0.0005 .

\section{Results and discussion}

The first test was performed at a constant load of $20 \mathrm{~N}$ under a variable frequency, ranging from $1 \mathrm{~Hz}$ to $100 \mathrm{~Hz}$. For a weakly parallel mode electromechanical coupled structure, the mechanical damping and coupling of a system is $\mathrm{C}=0.02923$ $\mathrm{N} / \mathrm{ms}, \theta=-0.000341090 \mathrm{~N} / \mathrm{V}$. The analytically calculated data is shown in Fig. 5.

From the Fig. 5 it can be observed that output voltage from the harvester increases up slowly and then decreases when the frequency of the harvester matches the resonance frequency. Resonance frequency of the harvester can be experimentally determined corresponding to the maximum power output [25]. The maximum output voltage of $4.435 \mathrm{~V}$ was calculated at $50 \mathrm{~Hz}, 20 \mathrm{~N}$ and $1 \Omega$ resistor. It has been investigated by other researchers that, to maximize the mean power output of the harvester, the mechanical damping should be kept minimum and the electromechanical coupling should be as maximum as possible [14].

Numerical simulation of similar model was carried out in

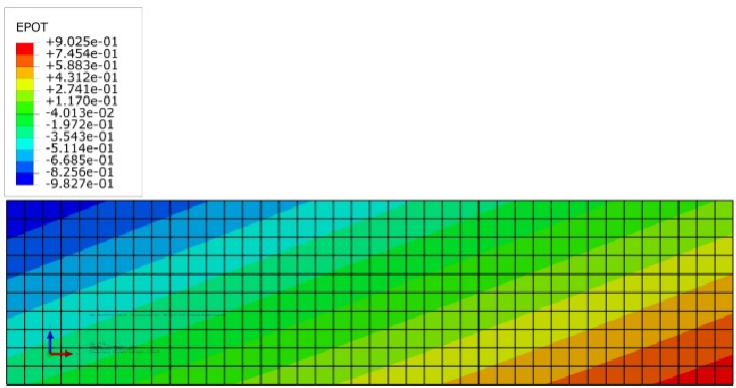

Fig. 6. Nodal solution of PZT-5A in ABAQUS.

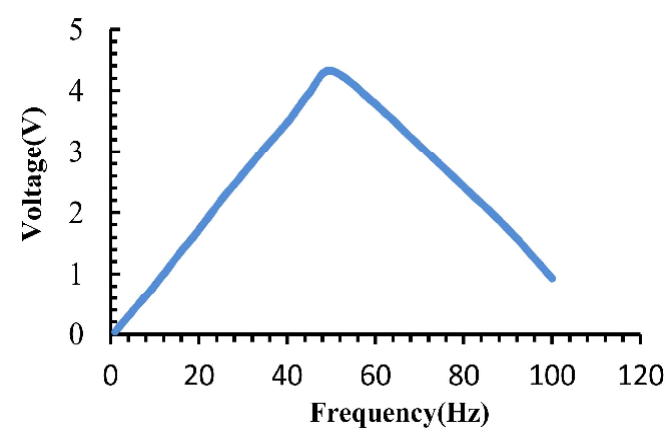

Fig. 7. Voltage response under variable frequency conditions.

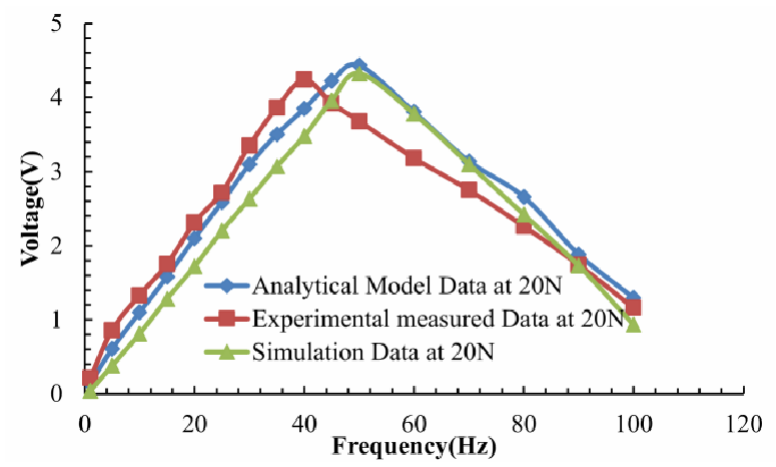

Fig. 8. Comparison of analytical, experimental and simulation results under variable frequency.

ABAQUS, the model has been discussed previously. Nodal solution of potential difference obtained from numerical simulation is shown in Fig. 6. The voltage response of a specimen at a constant load of $20 \mathrm{~N}$ and variable frequency range is shown in Fig. 7.

It can be observed from Fig. 7 that the output voltage from the harvester grows up slowly and then decreases when the frequency increases. The trend obtained from numerical simulation matched the trend of experimental data. Similar kind of response was observed during the vibration energy harvesting of cantilever beam with a proof mass [15].

In numerical simulation, maximum output voltage was obtained as $4.32 \mathrm{~V}$ at $50 \mathrm{~Hz}$ and $20 \mathrm{~N}$. The analytically calculated data compared with experimental and numerical simulation results to check the validity of the energy harvesting system is shown in Fig. 8. 


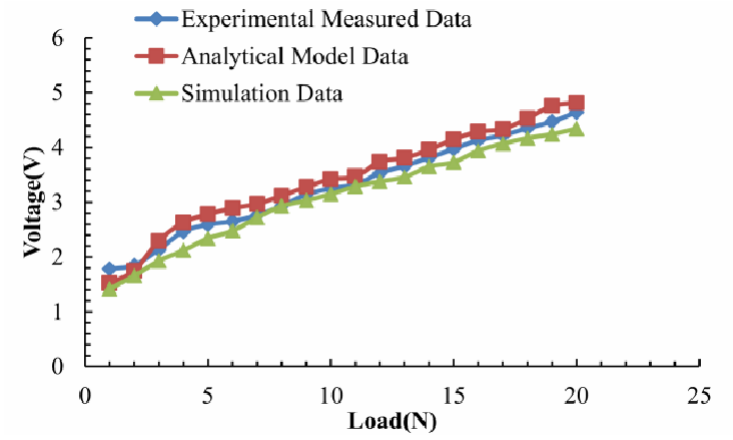

Fig. 9. Comparison of analytical, experimental and simulation results under variable loading.

Fig. 8 compares the analytical model data with the experimental and simulation results and good agreement was obtained at constant loading and different frequency conditions. It is observed that maximum voltage of 4.24 was obtained experimentally at a frequency of $40 \mathrm{~Hz}$, which numerical simulation and analytical calculations predict maximum voltage response with $2 \%$ error at $50 \mathrm{~Hz}$ vibrational frequency.

The second test was performed at a constant frequency of $1 \mathrm{~Hz}$ under variable loading conditions, ranging from $1 \mathrm{~N}$ to $20 \mathrm{~N}$. The comparison between analytical, experimental and numerical simulation results is shown in Fig. 9.

Fig. 9 validates the analytical calculated data at a constant frequency of $1 \mathrm{~Hz}$ under variable loading conditions. It was observed that by increasing loading at a constant frequency, the output voltage increases. Maximum error of $9.8 \%$ between numerical simulation data and experimentally observed results was recorded at $19 \mathrm{~Hz}$ frequency. It was observed that the developed analytical and numerical simulation models yield appropriate trends which correlate well with experimental data.

\section{Conclusion}

In the present work, a simple single degree of freedom analytical model was developed to determine the output voltage of Lead zirconate titanate (PZT-5A) at various frequency and loading conditions. The analytical model was verified on the basis of the experimental and simulation results. It was observed that:

(1) The rectangular shaped (PZT-5A) specimen at a constant load of $20 \mathrm{~N}$ and varying frequency from $1 \mathrm{~Hz}$ to $100 \mathrm{~Hz}$ results into increase in output voltage of the harvester till the resonance frequency.

(2) Maximum output voltage was obtained at $40 \mathrm{~Hz}$ frequency experimentally $50 \mathrm{~Hz}$ frequency analytically and numerically. Beyond $50 \mathrm{~Hz}$ it has a decreasing trend.

(3) At constant frequency of $1 \mathrm{~Hz}$ and varying load from $1 \mathrm{~N}$ to $20 \mathrm{~N}$, the output voltage of the harvester shows a continuously increasing trend.

(4) It was observed that the developed analytical and numerical simulation models yield appropriate trends which correlate well with experimental data with less than $10 \%$ error.
Since the maximum voltage was obtained at low frequency and greater loading conditions. So it is highly applicable to use Lead zirconate titanate (PZT-5A) in applications involving low frequency and higher loading conditions.

\section{Acknowledgment}

The authors acknowledge the research facility and financial support provided by University of Engineering and Technology Taxila, Punjab Pakistan during this research work.

\section{Nomenclature}

$\begin{array}{ll}t & : \text { Time } \\ v(t) & : \text { Voltage } \\ u(t) & : \text { Displacement of the mass } \\ y(t) & : \text { Displacement due to base excitation } \\ u(j w) & : \text { Displacement in frequency domain } \\ y(j w) & : \text { Displacement due to base excitation in frequency domain } \\ w & : \text { Angular frequency of the harvester } \\ \omega_{n} & : \text { Natural frequency of the harvester } \\ \theta & : \text { Electromechanical coupling coefficient } \\ K & : \text { Mechanical stiffness of the material } \\ R & : \text { Resistance } \\ C & : \text { Mechanical damping } \\ C_{p} & : \text { Capacitance of piezoelectric material }\end{array}$

\section{References}

[1] M. Soliman et al., A wideband vibration-based energy harvester, Journal of Micromechanics and Microengineering, 18 (11) (2008) 115021.

[2] K. Cook-Chennault, N. Thambi and A. Sastry, Powering MEMS portable devices - a review of non-regenerative and regenerative power supply systems with special emphasis on piezoelectric energy harvesting systems, Smart Materials and Structures, 17 (4) (2008) 043001.

[3] D. Vasic, Y.-Y. Chen and F. Costa, Self-powered piezoelectric energy harvester for bicycle, Journal of Mechanical Science and Technology, 28 (7) (2014) 2501-2510.

[4] A. Safari and E. K. Akdogan, Piezoelectric and acoustic materials for transducer applications, Springer Science \& Business Media (2008).

[5] W. Heywang, K. Lubitz and W. Wersing, Piezoelectricity: evolution and future of a technology, Springer Science \& Business Media, 114 (2008).

[6] K. N. Choi and H. H. Rho, Continuous energy harvesting method using piezoelectric element, 2015 IEEE 2nd International, Future Energy Electronics Conference (IFEEC) (2015).

[7] Z. Xiao et al., Energy harvester array using piezoelectric circular diaphragm for broadband vibration, Applied Physics Letters, 104 (22) (2014) 223904.

[8] X.-R. Chen et al., Vibration energy harvesting with a clamped piezoelectric circular diaphragm, Ceramics 
International, 38 (2012) S271-S274.

[9] E. Minazara, D. Vasic and F. Costa, Piezoelectric generator harvesting bike vibrations energy to supply portable devices, Proceedings of International Conference on Renewable Energies and Power Quality (ICREPQ'08), Santander, Spain (2008).

[10] K. Ahmed, EE462: Fundamentals of Control Systems Engineering.

[11] A. Tabesh and L. G. Fréchette, On the concepts of electrical damping and stiffness in design of a piezoelectric bending beam energy harvester, Proc. Power MEMS 2009 (2009) 368-371.

[12] T. Tanner and D. Inman, Combined shock and vibration isolation through the optimal control of hybrid 'smart'mount, Proc. 73rd Shock and Vibration Symp. (Newport Beach, RI) (2002).

[13] A. Erturk and D. J. Inman, Issues in mathematical modeling of piezoelectric energy harvesters, Smart Materials and Structures, 17 (6) (2008) 065016.

[14] S. Adhikari, M. Friswell and D. Inman, Piezoelectric energy harvesting from broadband random vibrations, Smart Materials and Structures, 18 (11) (2009) 115005.

[15] M. Fakhzan and A. G. Muthalif, Harvesting vibration energy using piezoelectric material: Modeling, simulation and experimental verifications, Mechatronics, 23 (1) (2013) 61-66.

[16] N. E. Dutoit, B. L. Wardle and S.-G. Kim, Design considerations for MEMS-scale piezoelectric mechanical vibration energy harvesters, Integrated Ferroelectrics, 71 (1) (2005) 121-160.

[17] A. Erturk and D. J. Inman, A distributed parameter electromechanical model for cantilevered piezoelectric energy harvesters, Journal of Vibration and Acoustics, 130 (4) (2008) 041002.

[18] F. Qayyum et al., Numerical simulation of thermal fatigue behavior in a cracked disc of AISI H-11 tool steel, Engineering Failure Analysis, 62 (2016) 242-253.

[19] Z. Anjum et al., Prediction of non-propagating fretting fatigue cracks in Ti6Al4V sheet tested under pin-in-dovetail configuration: Experimentation and numerical simulation, Materials \& Design, 87 (2015) 750-758.

[20] W. Wang et al., Application of different surrogate models on the optimization of centrifugal pump, Journal of Mechanical Science and Technology, 30 (2) (2016) 567-574.

[21] A. Moftakhari, C. Aghanajafi and A. M. C. Ghazvin, Thermal analysis of HVAC and solar panels using genetic optimization algorithm, Journal of Mechanical Science and Technology, 30 (3) (2016) 1405-1412.

[22] A. Saigal et al., Electrical response during indentation of a 1-3 piezoelectric ceramic-polymer composite, Journal of Applied Physics, 86 (1) (1999) 603-606.

[23] M. N. Ghasemi-Nejhad et al., Finite element method for active vibration suppression of smart composite structures using piezoelectric materials, Journal of Thermoplastic Composite Materials, 19 (3) (2006) 309-352.

[24] H. Allik and T. J. Hughes, Finite element method for piezoelectric vibration, International Journal for Numerical Methods in Engineering, 2 (2) (1970) 151-157.

[25] S. W. Ibrahim and W. G. Ali, Parametric identification for piezoelectric energy harvester (2013).

[26] A. Giannakopoulos and S. Suresh, Theory of indentation of piezoelectric materials, Acta Materialia, 47 (7) (1999) 21532164.

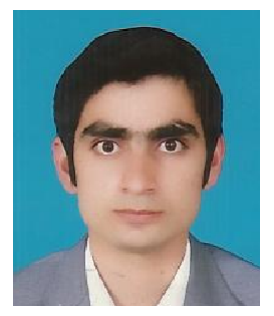

Zubair Butt was born in Sialkot, Pakistan, in 1988. He received his B.Sc. degree from UET Taxila, in 2012. He received his M.Sc. degree in Mechanical Engineering from UET Taxila, in 2015. Now he is working as a Lecturer in Department of Mechanical, Mechatronics and Manufacturing Engineering, UET Lahore Faisalabad Campus, Pakistan. His research interest includes the Energy harvesting terminology and MEMS system. 